\title{
Effect of Simulation Based Training on Maternity Nurses' Performance and Self-confidence Regarding Primary Postpartum Hemorrhage Management
}

\author{
Eman Mohamed Abd Elhakm*, Hemmat Mostafa Elbana \\ Obstetrics and Woman's Health Nursing, Faculty of Nursing, Benha University, Benha, Egypt \\ *Corresponding author: driman2014@gmail.com
}

Received August 12, 2018; Revised September 15, 2018; Accepted September 27, 2018

\begin{abstract}
Background: Simulation is one of the most important resources in nursing educational trading that help in improving nurses'performance and self-confidence for decreasing maternal morbidity and mortality from Postpartum haemorrhage (PPH). Aim: this study aimed to evaluate the effect of simulation based training on maternity nurses' performance and self-confidence regarding primary post-partum haemorrhage management. Research Design: A quasi-experimental design was used. Setting: This study was conducted in Clinical Obstetric Skill lab of Faculty of Nursing, Benha University. Sample: A convenient sample of a total 65 maternity nurse who working at Obstetrical and Gynaecological Emergency Department at Benha University Hospital. Tools: Three tools were used for collecting data; 1) A structured interviewing questionnaire; it includes two parts socio demographic data and assessment of maternity nurses' knowledge regarding primary postpartum haemorrhage. 2) Maternity nurses' practice observational checklist. 3) Modified Self-confidence measurement Scale. Results: The result of the present study proved that about two thirds (61.5\%) of the studied maternity nurses were aged less than 30 years with mean age of 29.6 \pm 7.62 years moreover the majority of them (86.2 \%) had less than 10 years of experience. It also indicates that the highest percentage (89.2\%) of them hadn't previous simulation training program regarding PPH. Additionally studied maternity nurse had poor level of knowledge, unsatisfactory performance and unconfident level of self-confidence mean score regarding management of PPH before simulation training (64.6\%, 78.5\%, 69.2\%) respectively. Yet, after the simulation training the nurses' knowledge, performance and self-confidence were significantly improved Conclusion: Hypotheses of the current study were accepted.Simulation based training had a highly significant effect on improvement nurses'performance (knowledge \& practice) and self-confidence regarding primary post-partum haemorrhage management. Recommendation:Simulation based training programs should be provided for all obstetrics health care givers to help nurses to play an active role in obstetric emergencies.
\end{abstract}

Keywords: simulation, maternity nurse, performance, self-confidence, post-partum hemorrhage

Cite This Article: Eman Mohamed Abd Elhakm, and Hemmat Mostafa Elbana, "Effect of Simulation Based Training on Maternity Nurses' Performance and Self-confidence Regarding Primary Postpartum Hemorrhage Management.” American Journal of Nursing Research, vol. 6, no. 6 (2018): 388-397. doi: 10.12691/ajnr-6-6-6.

\section{Introduction}

Simulation is the one of the most important learning modality in nursing field today. It is an artificial creation of real process for training and performance testing. Simulation goes beyond teaching and practicing psychomotor skills. It is an evidence-based strategy to facilitate high quality experiences that promote thinking and critical reasoning skills [1]. Simulation based training program enable nurses to experience a variety of clinical situations especially critical care procedure in a safe environment. When nurses are immerse them in the simulation scenario they are more engaged, experience a deeper learning and have unique opportunities to be able to apply the acquired knowledge into the clinical practice, develop technical clinical skills, a holistic behaviors approach, and, increased awareness of patient needs and more empowered to advocate for their patients [2].

Postpartum hemorrhage (PPH) is a common complication and potentially life-threatening obstetric emergency associated with both the vaginal birth and cesarean section. Indeed PPH is the leading causes of maternal morbidity and mortality in worldwide. Globally, 35\% of maternal deaths are associated with PPH. in Egypt, the maternal mortality ratio associated with $\mathrm{PPH}$ account 45 deaths per 100,000 live births in 2014 according to the World Health Organization [3].

Severe morbidity from PPH can be due to sequelae associated with more substantial blood loss, including ruptured uterus, severe hemorrhage, shock, septicemia, organ failure, venous and coagulopathy, acute respiratory distress syndrome, sepsis, anemia, intensive care, and prolonged hospitalization [4]. 
Postpartum hemorrhage ( $\mathrm{PPH})$ is commonly defined as blood loss exceeding $500 \mathrm{~mL}$ following vaginal birth and $1000 \mathrm{~mL}$ following cesarean. Definitions vary, however, and diagnosis of PPH is subjective and often based on inaccurate estimates of blood loss. Moreover, average blood loss at birth frequently exceeds 500 or $1000 \mathrm{ml}$. Proposed alternate metrics for defining and diagnosing $\mathrm{PPH}$ include change in hematocrit, need for transfusion, rapidity of blood loss, and changes in vital signs, all of which are complicated by the emergent nature of the condition [5].

The American college of obstetricians and gynecologists (ACOG) define postpartum hemorrhage as accumulative blood loss greater than or equal to $1,000 \mathrm{ML}$ or blood loss accompanied by signs or symptoms of hypovolemia within 24 hours after birth process include intrapartum loss regardless route of delivery [6]

According to [7] the four main causes of postpartum hemorrhage are uterine atony (70\%), trauma (20\%), retained tissue (10\%), and coagulopathy (1\%) [8] stated that the risk factors of $\mathrm{PPH}$ include poor management of third stage of labour, prolonged labour or augmented labour, pre eclampsia, previous postpartum hemorrhage, multiple gestation, multiparty, pregnancy induced hypertension, abruption placenta, placenta previa and absence of prenatal care.

PPH is often classified as Primary postpartum hemorrhage which is defined as loss of more than $500 \mathrm{ml}$ of blood within the first twenty-four hours of delivery or loss of any amount that is enough to cause hemodynamic instability in the mother or loss of more than $10 \%$ of the total blood volume. It is the most common form of postpartum hemorrhage. It occurs in $2-4 \%$ of all vaginal deliveries and $6-7 \%$ of cesarean deliveries. Secondary postpartum hemorrhage, on the other hand is defined as bleeding in excess of normal lochia after twenty-four hours and up to six weeks postpartum. In both the true loss is often underestimated due to the difficulty with the visual quantification [9].

Early detection and management, in a timely manner can be lifesaving. Measuring blood loss (MBL) is more accurate than visual estimation, therefore all blood loss should be measured and recorded following all births, When MBL reaches 500ml (minor PPH), Stage $1 \mathrm{PPH}$ Management should be commenced and help should be summoned from midwife in charge and first line obstetric and anesthetic staff. When MBL reaches 1000ml (major $\mathrm{PPH}$ ), Stage $2 \mathrm{PPH}$ Management should be commenced, and a multidisciplinary team should be summoned to attend (midwife in charge, obstetric anesthetic, senior obstetric registrar, healthcare support worker).When there is a PPH of more than $1500 \mathrm{ml}$ where the hemorrhage is continuing, Stage 3 should be commenced, the Massive Hemorrhage Protocol should be activated, and the consultant obstetrician should be asked to attend [10].

Self confidence in one's ability to effectively carry out a task within a specific situation is an important aspect of nursing practice and a focus of nursing education. Moreover, a person's belief in his self-confidence varies according to the 1) difficulty of the task, 2) certainty in performing a task at a given level of difficulty, and 3) extent to which the difficulty of the task generalizes across situations Because nursing is a contextually situated practice an individual's competence in any given clinical situation is derived from building a repertoire of experiences to inform clinical decision making [11].

Appropriate and an effective way simulation permits health professionals to inculcate skills and cultures in preparation for safe effective clinical care, whilst gaining confidence and becoming more efficient. Simulation is an educational device, not a place or a technology; it can be simple or complex. Also provides an environment similar to real-life situations. Student nurses can practice their skills on mannequins and models, without having any stress or anxiety [12].

Nurses are often the first line providers responding to postpartum haemorrhage because they are readily at the bedside. Equipping nurses with knowledge and techniques needed to identify the patient experiencing postpartum haemorrhage is essential in the management of postpartum haemorrhage for decreasing maternal morbidity and mortality caused by postpartum haemorrhage [13]. Also, immediate intervention is needed when $\mathrm{PPH}$ is diagnosed; the nurses should possess essential skills required for management of postpartum haemorrhage as fundal massage technique and measuring blood loss in case of uterine a tony which is a life-saving intervention [14].

\subsection{Significance of the Study}

Simulation training is a valuable method to improve maternity Nurses' knowledge, practice and self-confidence to save the women health outcome that are deteriorating from postpartum haemorrhage. Failure of the uterus to contract adequately after childbirth is the most common cause of postpartum hemorrhage. In the absence of timely and appropriate action, a woman could die within a few hours. In developing countries, mortality from $\mathrm{PPH}$ remains high and recent studies have shown that $\mathrm{PPH}$ causes up to 60 per cent of all maternal deaths. For example, in Egypt, the maternal mortality ratio associated with PPH account 45 deaths per 100,000 live births; PPH accounts for 59 per cent of maternal deaths in Burkina Faso, 53 per cent in the Philippines, and 43 per cent in Indonesia. PPH also causes considerable suffering for women and their families and places a heavy burden on national health systems [15]. Although most pregnancies and births are uneventful, approximately $15 \%$ of all pregnant women develop a potentially life-threatening complication that calls for skilled care and some will require a major obstetrical intervention to survive [16].

Postpartum haemorrhage (PPH) is a frequent complication of delivery and its incidence is commonly reported as $2-4 \%$ after vaginal delivery and $6 \%$ after caesarean section with uterine atony being the cause in about 50\% cases. $\mathrm{PPH}$ remains the number one killer of mothers and accounts about $28 \%$ of all maternal deaths in developing countries [15]. Multiple studies have suggested that many deaths associated with PPH could be prevented with prompt recognition and more timely and adequate treatment [16]. However, experience is difficult to acquire because of the rarity of cases, but may be gained in part through simulation.

\subsection{Aim of the Study}

The aim of the present study was to evaluate the effect of simulation based training on maternity nurses 'performance 
and self-confidence regarding primary post-partum hemorrhage management.

\subsection{Research Hypothesis}

H1- Maternity nurses exhibit higher knowledge score after attending simulation-based training program than before attending it.

H2- Maternity nurses exhibit higher practice score after attending simulation-based training program than before attending it.

H3- Maternity nurses exhibit higher self-confidence score after attending simulation-based training program than before attending it.

\section{Subject and Methods}

\subsection{Research Design}

Quasi experimental design was used for conducting the study (one group: pre/ post-test).

\subsection{Research Setting}

This study was conducted in Clinical Obstetric Skill lab of Faculty of Nursing, Benha University.

\subsection{Sampling}

Type: A convenient sample.

Size: A total of 65 maternity nurse who working in Obstetrical and Gynecological Emergency Department at time of data collection at Benha University Hospital.

\subsection{Tools of Data Collection}

Three tools were designed by the researchers after reviewing current \& past, local and international related literature by using periodicals journal, magazines, books and computer search to construct the tool of the study. The following tools were used for data collection:

\subsubsection{First Tool}

A structured interviewing questionnaire: it was consisted of two parts:

Part 1: Socio demographic data of studied sample including: (Age, Level of education, years of experience, Residence, Marital status, Job description, previous simulation training program participation).

Part 2: Assessment of maternity nurses' knowledge regarding primary postpartum hemorrhage, this sheet designed by researchers after extensive review of literature including: definition, causes, risk factors, types, complications, active management of third stage of labour and management of PPH (14 Questions).

\section{Scoring system for knowledge level:}

Incorrect answers (0), incomplete correct answers (1), complete correct answers (2), the total knowledge score was summed up and categorized as follows;

Poor $<60 \%$

Average $60-<75 \%$

Good $\geq 75 \%$

\subsubsection{Second Tool}

Maternity nurses' practice observational checklist:

Performance skills were measured using an objective structured clinical examination (OSCE). The OSCE is an instrument that provides an objective evaluation of a student's ability to perform clinical skills. A typical OSCE consists of 15 to 20 stations that assess nurses theoretical and practical level (performance skills).The practical stations consisted of a skills checklist adapted [17] guideline on management of postpartum haemorrhage, the practice checklist contains the individual steps or tasks in the sequence required to perform all the skills or activities being taught in a standardized way and include: Active management of the third stage of labour (AMTSL) 3 items, general management of PPH (9 items), Specific management of stages of PPH( 4 items).

Scoring system for performance level:

The maternity nurses' practice were scored as follow: 2 = done the step or task completely. 1 = done the step or task incompletely. $0=$ Not done. The total practice score was summed up and categorized as follows:

$\geq 60 \%$ Satisfactory.

$<60 \%$ Unsatisfactory.

\subsubsection{Third Tool}

\section{Modified Self-confidence measurement Scale}

Adapted from [18] .Self-confidence scale consist of 7-items that measures how confident nurses feel about the skills they practice when participating in the patient simulation experience. Items are measured on a three-point Likert scale (strongly disagree (0), disagree (1), agree (2). Total score of 0 to 7 is considered as unconfident and Total score of 8 to 21 is considered as confident.

\subsection{Methods}

This study was implemented according to the following steps:

\subsubsection{Approval}

An official approval to conduct this study was obtained from dean of faculty of nursing to Director of the university hospital, and then the researchers were interview each study participant and were obtain an informed consent before starting the data collection.

\subsubsection{Tools Validity}

Content validity was done by 5 jury from expertise in the field of maternity nursing and obstetric medicine specialty to assure content validity. The questionnaire modified according to the panel judgment on clarity of sentences and appropriateness of content.

\subsubsection{Tools Reliability}

The reliability was done by Cronbach's Alpha coefficient test which revealed that each of the three tools consisted of relatively homogenous items as indicated by the moderate to high reliability of each tool. The internal consistency of knowledge was 0.89. and the internal consistency of practice was 0.91 . While self-confidence was 0.81 . 


\subsubsection{Ethical Considerations}

All ethical issues were considered, the aim of the study explained to each nurse before applying the tools to gain their confidence and trust. An oral consent obtained from each nurse to participate in the study and withdraw when she needs. The study not having any physical, social or psychological risk on the participant. The data collected and treated confidentially.

\subsubsection{Pilot Study}

The pilot study carried out on $10 \%$ of total sample to evaluate efficiency, reliability and clarity of tools, no modifications were done then nurses involved in the pilot study were included in the main sample.

\subsubsection{Procedure}

Official permissions were taken to carry out the study. The aim of the study was explained to the selected subjects. Informed consents were obtained from selected subjects and the aim of the study was explained to them. Data were collected throughout the period from beginning of November 2017 till the end of April 2018 covering 6 months.

\section{Simulation based training program construction:}

This study conducted through the following sequential phases:

\section{1-Pre-Simulation Briefing/Orientation:}

A brief orientation to the room, equipment, staff as actors for the patient's partner/family or nurses, and simulator. This took approximately 5 minutes. Learning objectives are discussed i.e. care of patients with postpartum haemorrhage, communication, and leadership in a crisis. Postpartum Haemorrhage Clinical Checklist was reviewed. Basic instructions were learned to all participants:

1. Treat the scenario as real as possible

2. Use personal protection equipment (gloves, etc.) as needed

3. Request assistance if needed

4. Ask for medications if you feel that you need them

\section{2- Assessment phase}

The researchers introduce themselves and all maternity nurses were interviewed, the purpose of the study was explained by the researchers and an oral consent was taken to participate in the study, Then socio-demographic characteristics and baseline data about nurses" knowledge were collected using tool (I), time needed for nurses to fill this sheet was $25 \mathrm{~min}$. Nurses were asked to perform clinical skills procedures regarding management of primary postpartum hemorrhage before program implementation using tool (II), time needed to perform steps was 60 minutes for all procedures. Depending on the result of pre-test questionnaire for knowledge and performance, contents of simulation based training program were prepared and revised by 5 experts in the related field.

\section{3- Planning phase}

It was selected based on the program objectives \& maternity nurses' assessment needs. Study group received both theoretical part and simulation training about nursing management of primary $\mathrm{PPH}$ the simulator that was utilized was NOELLE birthing simulator (Gaumard
Scientific). This simulator required filling the blood reservoirs with a simulated blood product and then the bleeding started during the simulation scenario. The room prepared similar to a delivery room.

The simulator was put on an examination table, or bed with the lower torso draped depending on the scenario chosen. A delivery table may be available with the basic equipment available. IV tubing and IV fluids taped in place before the simulation begins. Place placenta in a delivery basin and then put some simulated blood on it for the scenario.

\section{4-Implementation phase}

The study group participants' were divided randomly into ten subgroups; which included 6 nurses twice weekly from 9.00.A.M to 3.00 P.M for the purpose of training course. The program was implemented in 10 weeks, each subgroup cover one week. - Put blood on the perineum and sheets underneath the simulator so there is no question about the presence of bleeding. - Make sure to have the simulator bleeding when the initial provider walks into the room so they see active bleeding during their initial evaluation. The initial estimated blood levels (EBLs) are explained in the clinical scenarios. The training course for each subgroup includes 2 hour theoretical with a 4hour practical. All theoretical sessions were followed by simulation training skills. The program sessions were implemented as follows:

\section{Theoretical and Training sessions:}

Session (1): included basic knowledge about primary $\mathrm{PPH}$ as definition, types, causes, signs \&symptoms, highrisk group, prevention during antenatal, labor, postpartum period, Complication. Followed by demonstrating nursing assessment for early detection and prevention.

Session (2): included active management of the third stage of labor (followed by simulation training with the proper scenario through demonstration \& re-demonstration of nurses' performance skills

Session (3): included nursing management of atonic postpartum followed by demonstration \&remonstration of nurses' performance skills in simulated virtual environment.

Debriefing: Immediately, following the simulation, researchers conducted debriefing as a reflective activity. This lasted about 30 minutes at the end of debriefing; the team was asked if there were any additional comments.

\section{Evaluation phase:}

After implementation of simulation based training program, the researchers were use the same previous assessment tool (I, II) to evaluate the effect of simulation on nurses' knowledge and performance skills in management of primary postpartum hemorrhage (Post-test). Also, nurses' self-confidence was evaluated using the self-confidence in Learning Scale (tool III) which measures how confident nurses feel about the skills they practice when participating in the patient simulation experience.

\subsubsection{Statistical Design}

The data were collected, organized, coded, computerized and analyzed by using appropriate statistical methods and tests( Mean and standard deviation for quantitative data, $\mathrm{X} 2$ for qualitative data and correlation tests) were used, data presented in suitable tables and figures using appropriate statistical techniques \& tests of significance. 


\section{Results}

Table 1: Reveals that about two thirds (61.5\%) of the studied maternity nurses were aged less than 30 years with mean age of $29.6 \pm 7.62$ years, more than half $(53.8 \%)$ of them had a secondary nursing education. In addition more than three quarters of them(78.5\%) had live in urban area and were married. moreover the majority of them (86.2 \%) had less than 10 years of experience. It also indicates that the highest percentage (89.2\%) of them hadn't previous simulation training program regarding $\mathrm{PPH}$.

Table 2: Shows that, there was a highly statistically significant difference in knowledge related to postpartum hemorrhage between the pre and post intervention phases $(\mathrm{p}<0.001)$.

Table 3: Indicates that, there was a highly statistically significant difference between studied nurses' practice related active management for postpartum haemorrhage between the pre and post intervention phases $(p<0.001)$.

Table 4: Indicates that, there was a highly statistically significant difference between studied nurses 'practice related to general management of postpartum haemorrhage between the pre and post intervention phases $(\mathrm{p}<0.001)$.

Table 5: Indicates that, there was a highly statistically significant difference between studied nurses' practice related to specific management for postpartum haemorrhage at both the pre and post intervention phases $(p<0.001)$.

Table 6: Shows that, there was a highly statistically significant difference between studied nurses' self-confidence between the pre and post intervention phases $(\mathrm{p}<0.001)$.

Table 7: Shows that, there was a highly positive association between studied nurse's total knowledge, Practice and self-confidence scores at post intervention phase.
Table 8: Shows that, there was a highly positive association between studied nurse's total practices and total self confidence among studied nurses at post intervention phase.

Table 1. Distribution of the studied nurses according to their general characteristics $(\mathrm{N}=65)$

\begin{tabular}{|c|c|c|}
\hline Variable & Frequency & $\%$ \\
\hline \multicolumn{3}{|l|}{ Age / years } \\
\hline - less than 30 years & 40 & 61.5 \\
\hline - 30-40 years & 14 & 21.5 \\
\hline - more than 40 years & 11 & 16.9 \\
\hline Mean \pm SD & \multicolumn{2}{|c|}{$29.6 \pm 7.62$} \\
\hline \multicolumn{3}{|l|}{ Educational level } \\
\hline - Secondary nursing education & 35 & 53.8 \\
\hline • Technical nursing education & 19 & 29.2 \\
\hline - Bachelor in nursing & 11 & 16.9 \\
\hline \multicolumn{3}{|l|}{ Residence } \\
\hline - Rural & 14 & 21.5 \\
\hline - Urban & 51 & 78.5 \\
\hline \multicolumn{3}{|l|}{ Marital status } \\
\hline • Unmarried & 14 & 21.5 \\
\hline - Married & 51 & 78.5 \\
\hline \multicolumn{3}{|l|}{ Job description } \\
\hline - Nurse & 35 & 53.8 \\
\hline • Supervisor & 17 & 26.2 \\
\hline • head nurse & 13 & 20.0 \\
\hline \multicolumn{3}{|l|}{ Years of experience } \\
\hline - less than 10 years & 56 & 86.2 \\
\hline - more than10 year & 9 & 13.8 \\
\hline Mean \pm SD & \multicolumn{2}{|c|}{$12.58 \pm 6.35$} \\
\hline \multicolumn{3}{|c|}{ Previous simulation training programs regarding $\mathrm{PPH}$} \\
\hline$\bullet$ no & 58 & 89.2 \\
\hline - Yes & 7 & 10.8 \\
\hline
\end{tabular}

Table 2. Distribution of knowledge regarding postpartum haemorrhage of studied nurses at different phases of the intervention ( $N=65)$

\begin{tabular}{|c|c|c|c|c|c|c|c|c|c|c|c|c|c|c|}
\hline \multirow{3}{*}{ Knowledge } & \multicolumn{6}{|c|}{ Pre intervention } & \multicolumn{6}{|c|}{ Post intervention } & \multirow{3}{*}{$\mathrm{X} 2$} & \multirow{3}{*}{ p-value } \\
\hline & \multicolumn{2}{|c|}{$\begin{array}{l}\text { complete } \\
\text { correct }\end{array}$} & \multicolumn{2}{|c|}{$\begin{array}{c}\text { Incomplete } \\
\text { correct }\end{array}$} & \multicolumn{2}{|c|}{ Incorrect } & \multicolumn{2}{|c|}{$\begin{array}{c}\text { complete } \\
\text { correct }\end{array}$} & \multicolumn{2}{|c|}{$\begin{array}{c}\text { Incomplete } \\
\text { correct }\end{array}$} & \multicolumn{2}{|c|}{ Incorrect } & & \\
\hline & No & $\%$ & No & $\%$ & No & $\%$ & No & $\%$ & No & $\%$ & No & $\%$ & & \\
\hline Definition of PPH & 7 & 10.8 & 35 & 53.8 & 23 & 35.4 & 51 & 78.5 & 14 & 21.5 & 0 & 0.0 & 65.3 & 0.000 \\
\hline Causes of PPH & 3 & 4.6 & 25 & 38.5 & 37 & 56.9 & 47 & 72.3 & 15 & 23.1 & 3 & 4.6 & 70.1 & 0.000 \\
\hline Risk factors of PPH & 4 & 6.2 & 16 & 24.6 & 45 & 69.2 & 58 & 89.2 & 5 & 7.7 & 2 & 3.1 & 92.1 & 0.000 \\
\hline Classification of PPH & 7 & 10.8 & 33 & 50.8 & 25 & 38.5 & 44 & 67.7 & 12 & 18.5 & 9 & 13.8 & 44.1 & 0.000 \\
\hline Definition of primary $\mathrm{PPH}$ & 15 & 23.1 & 38 & 58.5 & 12 & 18.5 & 51 & 78.5 & 14 & 21.5 & 0 & 0.0 & 42.7 & 0.000 \\
\hline Definition of secondary $\mathrm{PPH}$ & 7 & 10.8 & 33 & 50.8 & 25 & 38.5 & 42 & 64.6 & 21 & 32.3 & 2 & 3.1 & 47.2 & 0.000 \\
\hline Signs of $\mathrm{PPH}$ & 7 & 10.8 & 33 & 50.8 & 25 & 38.5 & 58 & 89.2 & 5 & 7.7 & 2 & 3.1 & 80.2 & 0.000 \\
\hline Assessment of PPH & 4 & 6.2 & 16 & 24.6 & 45 & 69.2 & 41 & 63.1 & 10 & 15.4 & 14 & 21.5 & 48.0 & 0.000 \\
\hline First3step management of PPH & 8 & 12.3 & 23 & 35.4 & 34 & 52.3 & 40 & 61.5 & 20 & 30.8 & 5 & 7.7 & 43.1 & 0.000 \\
\hline Active management of third stage of labour & 9 & 13.8 & 35 & 53.8 & 21 & 32.3 & 42 & 64.6 & 14 & 21.5 & 9 & 13.8 & 35.1 & 0.000 \\
\hline Follow up of a patient & 9 & 13.8 & 35 & 53.8 & 21 & 32.3 & 47 & 72.3 & 15 & 23.1 & 3 & 4.6 & 47.2 & 0.000 \\
\hline Complications of $\mathrm{PPH}$ & 7 & 10.8 & 33 & 50.8 & 25 & 38.5 & 43 & 66.2 & 16 & 24.6 & 6 & 9.2 & 43.4 & 0.000 \\
\hline Knowledge about uterotonics & 11 & 16.9 & 49 & 75.4 & 5 & 7.7 & 37 & 56.9 & 21 & 32.3 & 7 & 10.8 & 25.6 & 0.000 \\
\hline Stages of PPH & 9 & 13.8 & 35 & 53.8 & 21 & 32.3 & 39 & 60.0 & 20 & 30.8 & 6 & 9.2 & 31.1 & 0.000 \\
\hline
\end{tabular}

Table 3. Distributions of practice regarding active management of third stage of labour of studied nurses at different phases of the intervention (N=65)

\begin{tabular}{|c|c|c|c|c|c|c|c|c|c|c|c|c|c|c|}
\hline \multirow{3}{*}{ Items } & \multicolumn{6}{|c|}{ Pre intervention } & \multicolumn{6}{|c|}{ Post intervention } & \multirow{3}{*}{$\mathrm{X} 2$} & \multirow{3}{*}{ p-value } \\
\hline & \multicolumn{2}{|c|}{$\begin{array}{c}\text { Complete } \\
\text { done }\end{array}$} & \multicolumn{2}{|c|}{$\begin{array}{c}\text { Incomplete } \\
\text { done }\end{array}$} & \multicolumn{2}{|c|}{ Not done } & \multicolumn{2}{|c|}{$\begin{array}{c}\text { Complete } \\
\text { done }\end{array}$} & \multicolumn{2}{|c|}{$\begin{array}{c}\text { Incomplete } \\
\text { done }\end{array}$} & \multicolumn{2}{|c|}{ Not done } & & \\
\hline & No & $\%$ & No & $\%$ & No & $\%$ & No & $\%$ & No & $\%$ & No & $\%$ & & \\
\hline Administration of a Uterotonic Drug & 11 & 16.9 & 27 & 41.5 & 27 & 41.5 & 51 & 78.5 & 7 & 10.8 & 7 & 10.8 & 49.3 & 0.000 \\
\hline Controlled Cord Traction & 14 & 21.5 & 25 & 38.5 & 26 & 40.0 & 37 & 56.9 & 21 & 32.3 & 7 & 10.8 & 21.6 & 0.000 \\
\hline Uterine Massage & 7 & 10.8 & 27 & 41.5 & 31 & 47.7 & 44 & 67.7 & 19 & 29.2 & 2 & 3.1 & 53.7 & 0.000 \\
\hline
\end{tabular}


Table 4. Distributions of practice regarding general nursing management of PPH of studied nurses at different phases of the intervention $(\mathrm{N}=65)$

\begin{tabular}{|c|c|c|c|c|c|c|c|c|c|c|c|c|c|c|}
\hline \multirow{3}{*}{ Practice } & \multicolumn{6}{|c|}{ Pre intervention } & \multicolumn{6}{|c|}{ Post intervention } & \multirow{3}{*}{$\mathrm{X} 2$} & \multirow{3}{*}{ p-value } \\
\hline & \multicolumn{2}{|c|}{$\begin{array}{c}\text { Complete } \\
\text { done }\end{array}$} & \multicolumn{2}{|c|}{$\begin{array}{l}\text { Incomplete } \\
\text { done }\end{array}$} & \multicolumn{2}{|c|}{ Not done } & \multicolumn{2}{|c|}{$\begin{array}{l}\text { Complete } \\
\text { done }\end{array}$} & \multicolumn{2}{|c|}{$\begin{array}{l}\text { Incomplete } \\
\text { done }\end{array}$} & \multicolumn{2}{|c|}{ Not done } & & \\
\hline & No & $\%$ & No & $\%$ & No & $\%$ & No & $\%$ & No & $\%$ & No & $\%$ & & \\
\hline Initial actions to stop bleeding & 11 & 16.9 & 27 & 41.5 & 27 & 41.5 & 51 & 78.5 & 7 & 10.8 & 7 & 10.8 & 49.3 & 0.001 \\
\hline Resuscitation & 14 & 21.5 & 25 & 38.5 & 26 & 40.0 & 37 & 56.9 & 21 & 32.3 & 7 & 10.8 & 21.6 & 0.001 \\
\hline Monitoring and Assessing & 7 & 10.8 & 27 & 41.5 & 31 & 47.7 & 44 & 67.7 & 19 & 29.2 & 2 & 3.1 & 53.7 & 0.001 \\
\hline $\begin{array}{l}\text { Quantification of Blood Loss (QBL) } \\
\text { During vaginal Births }\end{array}$ & 14 & 21.5 & 29 & 44.6 & 22 & 33.8 & 37 & 56.9 & 18 & 27.7 & 10 & 15.4 & 17.4 & 0.001 \\
\hline $\begin{array}{l}\text { Quantification of Blood Loss (QBL) } \\
\text { During Caesarean Births }\end{array}$ & 12 & 18.5 & 29 & 44.6 & 24 & 36.9 & 37 & 56.9 & 17 & 26.2 & 11 & 16.9 & 20.7 & 0.001 \\
\hline Pharmacological and Fluid Therapy in PPH & 7 & 10.8 & 29 & 44.6 & 29 & 44.6 & 48 & 73.8 & 7 & 10.8 & 10 & 15.4 & 53.2 & 0.000 \\
\hline $\begin{array}{l}\text { Good communication between the } \\
\text { multi-disciplinary team }\end{array}$ & 4 & 6.2 & 19 & 29.2 & 42 & 64.6 & 31 & 47.7 & 18 & 27.7 & 16 & 24.6 & 32.5 & 0.000 \\
\hline Patient safety & 11 & 16.9 & 23 & 35.4 & 31 & 47.7 & 37 & 56.9 & 18 & 27.7 & 10 & 15.4 & 25.4 & 0.000 \\
\hline Evaluation and documentation & 37 & 56.9 & 21 & 32.3 & 7 & 10.8 & 12 & 18.5 & 27 & 41.5 & 26 & 40.0 & 24.4 & 0.000 \\
\hline
\end{tabular}

Table 5. Distributions of practice regarding specific management of PPH of studied nurses at different phases of the intervention (N=65)

\begin{tabular}{|c|c|c|c|c|c|c|c|c|c|c|c|c|c|c|}
\hline \multirow{3}{*}{ Practice } & \multicolumn{6}{|c|}{ Pre intervention } & \multicolumn{6}{|c|}{ Post intervention } & \multirow{3}{*}{$\mathrm{X} 2$} & \multirow{3}{*}{ p-value } \\
\hline & \multicolumn{2}{|c|}{$\begin{array}{c}\text { Complete } \\
\text { done }\end{array}$} & \multicolumn{2}{|c|}{$\begin{array}{c}\text { Incomplete } \\
\text { done }\end{array}$} & \multicolumn{2}{|c|}{ Not Done } & \multicolumn{2}{|c|}{$\begin{array}{c}\text { complete } \\
\text { done }\end{array}$} & \multicolumn{2}{|c|}{$\begin{array}{c}\text { Incomplete } \\
\text { done }\end{array}$} & \multicolumn{2}{|c|}{ Not Done } & & \\
\hline & No & $\%$ & No & $\%$ & No & $\%$ & No & $\%$ & No & $\%$ & No & $\%$ & & \\
\hline $\begin{array}{l}\text { 1. Stage } 1 \text { PPH Normal vital signs and } \\
\text { lab values }\end{array}$ & 11 & 16.9 & 27 & 41.5 & 27 & 41.5 & 51 & 78.5 & 7 & 10.8 & 7 & 10.8 & 49.3 & $0.001^{*}$ \\
\hline $\begin{array}{l}\text { 2. Stage } 2 \text { of continued bleeding } \\
\text { estimated blood level up to } 1500 \mathrm{ml} \text { or } \\
\text { any patient requiring } \geq 2 \text { uterotonics }\end{array}$ & 14 & 21.5 & 25 & 38.5 & 26 & 40.0 & 37 & 56.9 & 21 & 32.3 & 7 & 10.8 & 21.6 & $0.001^{*}$ \\
\hline $\begin{array}{l}\text { 3. Stage } 3 \text { PPH Abnormal vital signs, } \\
\text { lab values and Oliguria }\end{array}$ & 7 & 10.8 & 27 & 41.5 & 31 & 47.7 & 44 & 67.7 & 19 & 29.2 & 2 & 3.1 & 53.7 & $0.001^{*}$ \\
\hline $\begin{array}{l}\text { 4. Stage } 4 \text { PPH massive haemorrhage } \\
\text { with cardio vascular collapse }\end{array}$ & 16 & 24.6 & 24 & 36.9 & 25 & 38.5 & 46 & 70.8 & 10 & 15.4 & 9 & 13.8 & 27.8 & $0.001^{*}$ \\
\hline
\end{tabular}

Table 6. Distribution of studied nurses 'self-confidence regarding PPH at different phases of intervention (N=65)

\begin{tabular}{|c|c|c|c|c|c|c|c|c|c|c|c|c|c|c|}
\hline \multirow{3}{*}{ Items } & \multicolumn{6}{|c|}{ Pre intervention } & \multicolumn{6}{|c|}{ Post intervention } & \multirow{3}{*}{$\mathrm{X} 2$} & \multirow{3}{*}{ p-value } \\
\hline & \multicolumn{2}{|c|}{ Agree } & \multicolumn{2}{|c|}{ Disagree } & \multicolumn{2}{|c|}{$\begin{array}{l}\text { Strongly } \\
\text { disagree }\end{array}$} & \multicolumn{2}{|c|}{ Agree } & \multicolumn{2}{|c|}{ Disagree } & \multicolumn{2}{|c|}{$\begin{array}{l}\text { Strongly } \\
\text { disagree }\end{array}$} & & \\
\hline & No & $\%$ & No & $\%$ & No & $\%$ & No & $\%$ & No & $\%$ & No & $\%$ & & \\
\hline $\begin{array}{l}\text { 1. I am confident that I am mastering the content of } \\
\text { the training activity }\end{array}$ & 8 & 12.3 & 38 & 58.5 & 19 & 29.2 & 41 & 63.1 & 17 & 26.2 & 7 & 10.8 & 35.7 & $0.00^{\star}$ \\
\hline $\begin{array}{l}\text { 2. I am confident that the training covered critical } \\
\text { content }\end{array}$ & 4 & 6.2 & 47 & 72.3 & 14 & 21.5 & 48 & 73.8 & 15 & 23.1 & 2 & 3.1 & 62.7 & $0.00^{\star}$ \\
\hline $\begin{array}{l}\text { 3. I am confident that I am developing skills \& } \\
\text { obtaining the required knowledge }\end{array}$ & 12 & 18.5 & 40 & 61.5 & 13 & 20 & 30 & 46.2 & 32 & 49.2 & 3 & 4.6 & 14.8 & $0.00^{\star}$ \\
\hline $\begin{array}{l}\text { 4. My instructors used helpful resources to teach } \\
\text { this simulation. }\end{array}$ & 16 & 24.6 & 37 & 56.9 & 12 & 18.5 & 37 & 56.9 & 26 & 40.0 & 2 & 3.1 & 17.3 & $0.00^{\star}$ \\
\hline $\begin{array}{l}\text { 5. It is my responsibility as the student to learn } \\
\text { what I need to know from this method of training. }\end{array}$ & 17 & 26.2 & 38 & 58.5 & 10 & 15.4 & 35 & 53.8 & 18 & 27.7 & 12 & 18.5 & 13.5 & $0.00^{\star}$ \\
\hline $\begin{array}{l}\text { 6. I know how to get help when I do not understand } \\
\text { the concepts covered in the simulation. }\end{array}$ & 8 & 12.3 & 42 & 64.6 & 15 & 23.1 & 33 & 50.8 & 25 & 38.5 & 7 & 10.8 & 22.4 & $0.00^{*}$ \\
\hline $\begin{array}{l}\text { 7. I know how to use simulation activities to learn } \\
\text { critical aspects of these skills. }\end{array}$ & 9 & 13.8 & 44 & 67.7 & 12 & 18.5 & 32 & 49.2 & 26 & 40.0 & 7 & 10.8 & 18.8 & $0.00^{*}$ \\
\hline
\end{tabular}

Table 7. Correlation between total knowledge, total practices and total self confidence among studied nurses

\begin{tabular}{|c|c|c|c|c|}
\hline \multirow{2}{*}{ Practices } & \multicolumn{4}{|c|}{ Knowledge } \\
\cline { 2 - 5 } & \multicolumn{2}{|c|}{ Pre } & \multicolumn{2}{c|}{ Post } \\
\cline { 2 - 5 } & $\mathbf{r}$ & p-value & R & p-value \\
\cline { 2 - 5 } & 0.32 & 0.008 & 0.73 & 0.000 \\
\hline Self confidence & 0.54 & 0.002 & 0.64 & 0.05 \\
\hline
\end{tabular}

Table 8. Correlation between total practices and total self confidence among studied nurses at different phases of intervention

\begin{tabular}{|c|c|c|c|c|}
\hline \multirow{2}{*}{$\begin{array}{c}\text { Total Self } \\
\text { confidence }\end{array}$} & \multicolumn{3}{|c|}{ Pre } & \multicolumn{2}{c|}{ Post } \\
\cline { 2 - 5 } & $\mathrm{R}$ & $\mathrm{p}$-value & $\mathrm{R}$ & $\mathrm{p}$-value \\
\cline { 2 - 5 } & 0.68 & 0.006 & 0.86 & 0.000 \\
\hline
\end{tabular}


Figure 1: Percentage distribution of total knowledge score of the studied nurses at different phases of the intervention However, the level of knowledge before program implementation was mainly poor among studied nurse regards all aspects of knowledge. Yet, after program implementation, level of knowledge was mainly good.

Figure 2: Percentage distribution of total practice score of the studied nurses at different phases of the program. However, more than three quarters of studied nurse had unsatisfactory performance level before simulation program. Yet after simulation near majority of them had satisfactory performance level.

Figure 3: Percentage distribution of studied group regarding total self-confidence of the studied nurses at different phases of the program. However, the self-confidence before program implementation was mainly low and unconfident while after simulation the studied nurse accentuate significant progress in all domains of self-confidence.



Figure 1. Percentage distribution of total knowledge score of studied nurses at different phases of intervention $(\mathrm{N}=65)$

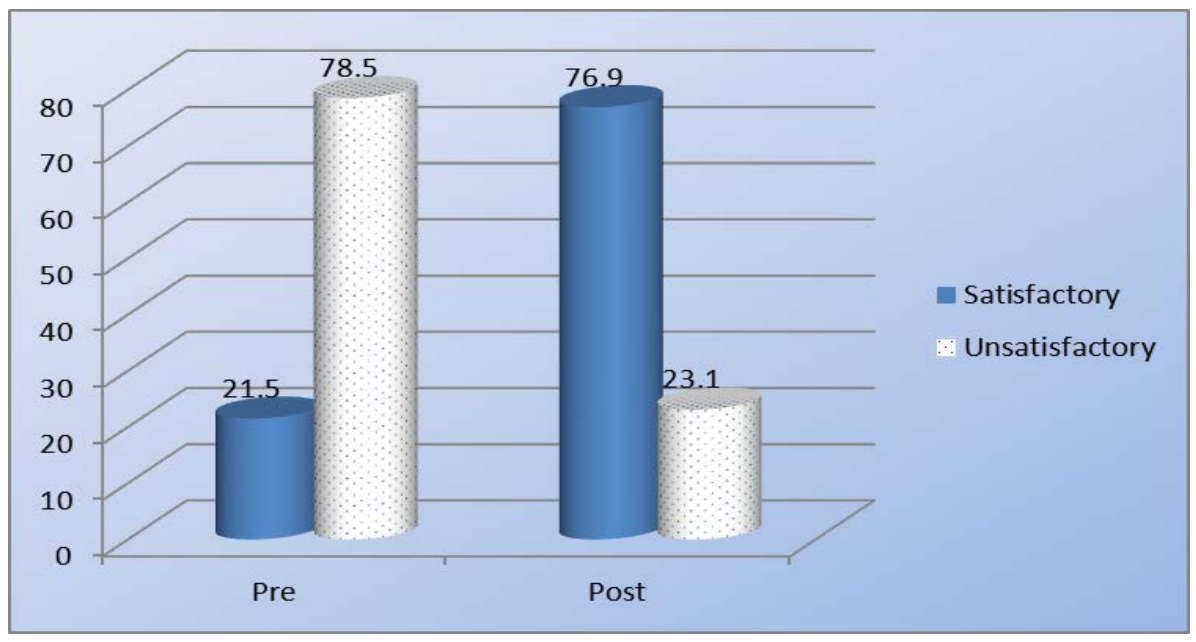

Figure 2. Percentage distribution of total practice score of studied nurses at different phases of intervention



Figure 3. Percentage distribution of studied group regarding total self-confidence score 


\section{Discussion}

Simulation training has been found to reduce level of anxiety and stress in emergency situations. Training on practical skills, such as diagnosis and management of $\mathrm{PPH}$ and related processes have been found to improve mental preparedness and confidence in the ability of the nurse to implement the acquired clinical skills effectively; Simulation training is a valuable method to improve maternity nurses performance skills and self-confidence for saving the women health outcome who are deteriorating from postpartum hemorrhage [19].

Nurses with improved knowledge and skills have a higher level of self-confidence, thus improving their ability to provide safe and effective quality care to postpartum patients. The increased self-confidence, knowledge and skills have the potential to reduce PPH related complications and mortality [20]. The current study aimed to evaluate the effect of simulation based training on maternity nurses' performance skills and self-confidence regarding primary post-partum hemorrhage management in Clinical Obstetric Skill lab of Faculty of Nursing at Benha University.

Regarding the socio-demographic characteristics of the maternity nurses, the present findings showed that more than two thirds of studied maternity nurses had age less than 30 years with mean age of 29.6 \pm 7.62 years.More than half of them had a secondary nursing education. The majority of them had less than 10 years of experience. In addition more than three quarters of them had live in urban area and were married. These study findings are disagreed with [21]in the study at Sudan to evaluate Knowledge and Practice of Nurse Midwives Regarding Management and Prevention of Postpartum Hemorrhage. It was reported that the most common age group was 47-55 years and Nurses mostly had experience of 21 years or more.

In addition, the result of the current study showed that the majority of nurses hadn't previous simulation training course related PPH this result is in accordance with [21] who reviewed that, only one third of them received in-service training about PPH. On the other hand [22] in the study to investigate the effect of a medium fidelity simulation based training on nurses' knowledge, Performance and Clinical Judgment of Postpartum Hemorrhage Management at Alexandria University. It stated that more than half of studied maternity nurse attend emergency obstetric training regarding $\mathrm{PPH}$.

Additionally, the finding of the present study proved more than two thirds of studied maternity nurses' had poor level of knowledge regarding all knowledge items concerning postpartum hemorrhage at pre intervention phase. These findings may be due to that there is lack of implementing educational training program regarding postpartum hemorrhage at the studied setting. These results is in contrast with [22] who Indeed that around two-thirds of both groups had fair and good level of general knowledge before simulation training. This result may be attributed to the fact that the participants attend periodic didactic courses of obstetrics emergency including $\mathrm{PPH}$ within previous five years. Also [23] who reported in his study of Assessment of knowledge of strategies used in the prevention and management of postpartum hemorrhage by midwives in Bayelsa State, Nigeria has showed high level of Knowledge about PPH among nurses.

Concerning effect of simulation based training program on maternity nurse's knowledge, the present study findings illustrated that there was significantly improvement of nurses' knowledge post intervention compared to pre intervention. In addition the present study findings represented that there was significantly increase of total knowledge score post intervention. These findings agreed with [24] who found that educational programs (both simulation and didactic) for the prevention and management of $\mathrm{PPH}$ led to significant improvements in the knowledge of obstetric nurses.

Similarly this result is in agreement with [25] they examining knowledge gained through simulation training, participant demonstrated a significant increase and sustained of midwives knowledge following simulation training. Similarly [26] concluded that simulation-based training consider as an effective educational strategy that to manage obstetric emergencies on live patients in working environment which can further help in improvement of knowledge, skills as well as increase itself-confidence also to recognize and avoid pitfalls in managing such emergencies in real life scenario. Also this finding is supported by [27] they pointed out that the use of simulation training as a preferred educational technique, notably they reported that training based on patient simulators and real patients simulation, help to promote cognitive knowledge.

As regard the practice related to postpartum hemorrhage among maternity nurses, the present study findings proved that the more than three quarters of the studied maternity nurses had un satisfactory practice regarding $\mathrm{PPH}$ at preprogram phase, which has been become more satisfactory post intervention. Additionally In relation to the studied maternity nurse's practice regarding to active management of third stage of labour the study finding represented that, nurses had unsatisfactory practice at pre intervention phase and highly improved immediately post intervention.

These finding was in same line with [28] they reported that the level of nurses' performance regarding their role in active management of third stage of labor (AMTSL) was unsatisfactory before attending simulation training program. While post training there was a significant improvement. Relevant with this results [26] confirmed that the routine use of AMTSL reduced the incidence of $\mathrm{PPH}$, the amount of blood loss, the need for blood transfusion and additional Uterotonics, and therefore should be included in any intervention program to reduce deaths by $\mathrm{PPH}$, This result is in accordance with [29] who reports that simulation-based teaching-learning method reflects significantly higher performance in simulation group among nurses taught about obstetrical emergencies compared to didactic teaching and those learning by means of observed practice.

In relation to the practice of studied maternity nurses regarding to general management of $\mathrm{PPH}$ that include Resuscitation, Communication (call for help). Monitoring \&Investigation the study finding represented that there were significantly improved in maternity nurses practice after simulation program. This results indicates that nurses never attends resuscitation training including basic life supports, restoration of blood volume and restoration 
of oxygen-carrying capacity for women during their reproductive life. This result is in line with [30] they reported that before postpartum hemorrhage simulation training, lack of knowledge and skill on management of $\mathrm{PPH}$, delay to transfer the patient to the operating room and a poor communication between different professionals were identified. Post simulation using emergency care simulator, an improvement in participant's resuscitation technique, enhancing emergency technical skills, improvement in knowledge, team spirit and structured communication.

In relation to the studied maternity nurse practice regarding specific management of $\mathrm{PPH}$ the study finding represented that nurses had unsatisfactory practice at pre intervention phase and highly improved immediately post intervention. Moreover the present study findings showed that the total practice score of the studied nurses regarding $\mathrm{PPH}$ was unsatisfactory at pre intervention and become more satisfactory at post intervention. These results demonstrates a model for the effective and efficient use of simulation-based training which inductively permit the nurses to participate in simulated environment using relevant and realistic $\mathrm{PPH}$ scenarios. This result is in line with the study of [24] they stated that simulation-based teaching is a better modality of teaching learning especially for obstetric emergency situation than didactic lectures. Thus substantial improvement of overall skills among simulated group who performance far better in obstetric emergency situation than didactic lecture group on their first encounter with live patients.

As regarding the studied maternity nurse's self-confidence the present study findings represent that there were a highly statistically significant difference between studied nurses' self-confidence at the pre and post intervention phases. These findings are also consistent with [31] who studied the effect of clinical simulation on student nurse level of confidence, revealed that half of the nursing students believed that working with patient simulation increased their confidence, clinical competence, and prepared them for real clinical settings. A similar study was done by [32] showed that nursing students expressed positive attitudes toward the simulation-based course. They agreed that the simulation was motivating and effective. Participants also expressed satisfaction toward the resources used during the simulation. They were confident in their mastery of skills and knowledge covered in the simulation and in their ability to apply this content to clinical settings. They also felt it was their own responsibility to determine what was to be learned from the simulation.

On the same line with a research, done by [33] who showed that using the simulation technique leads to satisfaction and self-confidence. Nurses' self-confidence has a significant impact on their understanding and feeling of success in their clinical practices. Moreover In the research of [34] they pointed out that a significant increase was observed in the level ofnursing students' confidence, who were trained clinical skills using simulation, compared to the traditional training group in areas such as diagnosis and symptoms of disease, patient assessment, nursing interventions, and evaluation.

Moreover the findings of present study revealed that the total self-confidence score of the studied nurses regarding $\mathrm{PPH}$ was unsatisfactory at pre intervention and become more satisfactory at post intervention, these results agreed with [35] indicated the nurse s' self-confidence score showed a significant increase in the simulation group after the intervention compared to pre intervention.

Furthermore, the results of the current study showed that there was a highly positive association between studied nurse's total knowledge, practice and self-confidence scores at post intervention phase. Also that there was a highly positive association between studied nurse's total practices and total self-confidence the findings of present study were in the same line with [36] who reported that there were positive association between knowledge and performance and self-confidence also revealed that nurses integrated their knowledge and experience for making accurate clinical judgments and thus increase their selfconfidence. In addition, the simulation training permits opportunities to capture the essential knowledge and skills for developing self-confidence.

\section{Conclusion}

Based on the study findings of the current study; the study concluded that research hypothesis were supported and simulation based training program had a highly significant effect on improvement performance skills and self-confidence for maternity studied nurses regarding management of primary postpartum hemorrhage. Also, there was a highly positive association between studied nurse's total knowledge, Practice and self-confidence scores at post intervention phase.

\section{Recommendations}

In the light of the findings of current study the following recommendations were be suggested:

1-Simulation based training programs should be provided for all obstetrics health care givers to help nurses to play an active role in obstetric emergencies.

2-simulation training program should be included in nursing curriculum to increase nurse knowledge, performance skills, for early detection rapid effective nursing response for managing $\mathrm{PPH}$

\section{Future Researches}

Explore the effect of application of simulation program for maternity nurses on improving $\mathrm{PPH}$ cases outcome.

\section{Acknowledgements}

The researchers would like to express gratitude and appreciation to all nurses who participated in this study for their effective cooperation.

\section{References}

[1] Jeffries, P. R. (2016). The NLN Jeffries Simulation Theory. Philadelphia, Pennsylvania: Wolters K luwer. 
[2] Ogden PE, Cobbs LS, Howell MR, SibbittSJ,DiPette DJ.. Clinical simulation: importance to theinternal medicine educational mission. Am J Med.2015; 203(63): 340-346.

[3] World health organization (WHO):WHO Library Cataloguing-inPublication Data. World health statistics. (2014)Available on the WHO website (www.who.int).

[4] Zelop CM: Postpartum hemorrhage: becoming more evidencebased. (2011). ObstetGynecol.. Jan; 117: 3-5.

[5] Rath WH.. Postpartum hemorrhage-update on problems of definitions and diagnosis. (2013). Acta Obstet Gynecol Scand May; 90(5): 421-8.

[6] Menard MK,Main EK Currigan SM, :Executive summary of the re VITAlize initiative :Standardizing obstetric data definition.(2014). Obstet. gynaecol: 124: 150-3.

[7] Anderson, J.M \& Etches, D. (2016). Prevention and management of post partum hemorrhage. America family physician, 75(6): 860-865.

[8] Humaira, N., Anisa, f. \&aziz, N.U. Post partum hemorrhage: Source: Amy's Nursing Blog (2010). OB/GYN 4 - Postpartum Nurse. 20(2)

[9] Devi, K.P., Singh, L.R., Singh, L.B., Singh, M.R. and Singh, N.N (2015). Postpartum Hemorrhage and Maternal Deaths in North East India. Open Journal of Obstetrics and Gynecology, 5 , 635-638.

[10] Obstetric bleeding strategy for Wales (OBS) (2017). Prevention and management of post partumhemorrhage, maternity network Wales.

[11] Fisher D, King L. An integrative literature review on preparing nursingstudents through simulation to recognize and respond to the deteriorating patient. Journal of Advanced Nursing. 2013 Nov; 69(11): 2375-88.

[12] Kordi, M., RashidiFakari, F., Khadivzadeh, T., Mazloum, S. R., Akhlaghi, F., \& Tara, M. (2015). The Effect of Web-based and Simulation-based Education on Midwifery Students' SelfConfidence in Postpartum Hemorrhage Management. Journal of Midwifery and Reproductive Health, 3(1), 262-268.

[13] Gabel T.A.andWeeber:Measuring and communicating blood loss during obstetric hemorrhage. journal of Obstetrics, Gynecologic \& Neonatal Nursing, 41(4) (2012), pp 551-558.

[14] Cohain, J. (2012). A Novel Way to Prevent Postpartum Hemorrhage. Midwifery Matters. Academic Journal, 135, 21.

[15] World Health Organization. WHO (2015). Recommendations for the prevention and treatment of postpartum haemorrhage [Internet]. Genève: WHO; [cited Aug 20].

[16] Haimee E L, Maria de L de Souza, SabihaKh, NajmaNaz, Anna Carolina RaduenzHuf Souza.(2016). The Practice of Nursing in the Prevention and Control of Postpartum Hemorrhage: An Integrative Review. American Journal of Nursing Science.Vol. 5, No. 1, P.p: 8-15.

[17] Health Service Executive, (2016). Guideline on Management of Postpartum Hemorrhage, home birth service, revision No. 1.

[18] National League for Nursing. Outcomes and competencies for graduates of practical/vocational, diploma, baccalaureate, master's and research doctorate programs in nursing. New York, NY: National League for Nursing; 2012.

[19] Kordi, M., RashidiFakari, F., Khadivzadeh, T., Mazloum, S. R. Akhlaghi, F., \& Tara, M. (2015). The Effect of Web-based and Simulation-based Education on Midwifery Students' SelfConfidence in Postpartum Hemorrhage Management. Journal of Midwifery and Reproductive Health, 3(1), 262-268.
[20] Sathiyalatha, S. Effectiveness of educational intervention package regarding postpartum management. (2015). The Journal of Nursing Trendz, 6 (3), 12-15.

[21] Faiza.A.N: Knowledge and Practice of Nurse Midwives Regarding Management and Prevention of Postpartum Hemorrhage in Three Selected Teaching Hospitals-Khartoum State-Sudan 2015. Ind $J$ of Appl Res, 5(4): 634-8.

[22] Zaky. N H Effect of a Medium Fidelity Simulation Based Training on Nurses' Knowledge, Performance and Clinical Judgment of Postpartum Hemorrhage Management (2017): at Alexandria University.

[23] Onasoga, Olayinka A., Awhanaa, Akpomeyoma Tare Amiegheme Felicia Ehobhayi: Assessment of knowledge of strategies used in the prevention and management of postpartum haemorrhage (2012) by midwives in Bayelsa State, Nigeria 4 (1):447-453.

[24] Kumar N, Kant N, and Samar S. :Role of Simulation-based teaching in Management of Postpartum Hemorrhage amongst Postgraduate Students of Department of Obstetrics and Gynecology:; (2016): A Prospective Study future of medical education journal.; (1):31-35.

[25] Ayres C, Deering, D.. Siassakos. Sustaining simulation training programs-experience from maternity care. (2011). Br. J. Obstet. Gynecol., 118 pp. 22-26.

[26] Ameh C, Adegoke A, Hofman J. (2012). The impact of emergency obstetric care training in Somaliland, Somalia. IntGynaecol Obstet.; 117: 283-87.

[27] Agha S, AlhamraniA, Khan M.:Satisfaction of medical students with simulation-based learning. (2015). Saudi Med J. 36(6): 73136.

[28] Sandeep S, Indu L. Simulation training in the management of obstetric emergencies. A review of the literature. (2014). Rev Med Brux. Nov-Dec; 35(6):491-8.

[29] Bogne V., Kirkpatrick C., Englert Y.:Simulation training in the management of obstetric emergencies. A review of the literature. (2014). Revue Medicale de Bruxelles. 35(6):49198.

[30] Evans CL, Johnson P, Bazant E, Bhatnagar N, Zgambo J, Khamis AR. :Competency-based training "Helping Mothers Survive: Bleeding after Birth" for providers from central and remote facilities in three countries. (2015).. ActaObstetGynecol Scand. 94(3): 316-23.

[31] Nahas, Nour., Al-Nobani, :Teaching in Nursing: A guide for faculty (3rd ed.). (2013) Saint Louis: Elsevier.

[32] Adamson, K.A., Kardong-Edgren, S., \&Willhaus, J. An Updated Review of Published Simulation Evaluation Instruments. (2013). Clinical Simulation in Nursing, 9(9), e393-e400.

[33] Parker RA, McNeill JA, Pelayo LW, Goei KA, Howard J, Gunter MD.Pediatric clinical simulation: a pilot project. (2011). J Nurs Educ.; 50(2): 105-11.

[34] Thomas C, Mackey E:Influence of a clinical simulation elective on baccalaureate nursing student clinical confidence. (2012). J Nurs Educ.; 51(4):236-9.

[35] Leila V, Abolghasem A, Eskandar F, Shahrzad G, and Bahareh A The Effect of Simulation Teaching on Baccalaureate Nursing Students' Self-confidence Related to Peripheral Venous Catheterization in Children,(2013)..A Randomized Trial; J Caring Sci. Jun; 2(2): 157-164.

[36] Lindsey PL, Jenkins S: Nursing students' clinical judgmen regarding rapid response: the influence of a clinical simulation education intervention. (2013). Nurs Forum. 48(1): 61-7. 